\title{
Protecting against Clostridium difficile illness
}

Background and epidemiology:

A gram-positive, anaerobic bacterium that is common in the environment, Clostridium difficile is transmitted by the fecal-oral route. Its resistant spores are ingested, survive passage through the stomach and ultimately reside in the colon. ${ }^{1}$ Antimicrobial therapy disrupts the ecosystem of stool flora, which fosters $C$. difficile overgrowth.

Clinical symptoms range from none (asymptomatic carriage) to watery diarrhea to lifethreatening pseudomembranous colitis. The incidence of $C$. difficile carriage, about $1 \%-3 \%$ among healthy adults, is higher among hospital employees and those working with susceptible patients. The rate increases to about $20 \%$ with antibiotic use. As many as $31 \%$ of high-risk patients in hospital are colonized with $C$. difficile, with only a subset becoming symptomatic. ${ }^{1}$

C. difficile-associated diarrhea tends to become a problem in hospitals, nursing homes and other long-term care facilities. Disease severity depends on the pathogenicity of the strain as well as the individual patient's risk factors: use of antibiotic therapy (particularly macrolides, third- and second-generation cephalosporins, clindamycin and quinolones, but also including flagyl and vancomycin), ${ }^{2}$ advanced age, underlying illness (especially inflammatory bowel disease), institutional setting; and immunodeficiency due to HIV infection or chemotherapy. Recent outbreaks in Canada, the United Kingdom and the United States suggest that infections - are more common than had been suspected, or that new strains have emerged that are more invasive or pathogenic.

Various strains of $C$. difficile possess multiple virulence factors that aid in adherence and colonization, such as flagellar proteins, surface-layer proteins and surface-exposed adhesion proteins. Pathogenic strains of $C$. difficile express 1 or 2 large exotoxins, conventionally identified as A and B - although emerging epidemiologic data also point to a bivalent protein, yet to be fully characterized, that is associated with more severe forms of the illness.

Oligosaccharide receptors for toxin $\mathrm{A}$ are expressed on the apical membranes on intestinal epithelia; a toxin $\mathrm{B}$ receptor has yet to be identified. Purified toxin A shows enterotoxic and proinflammatory activity. The A and $\mathrm{B}$ toxins appear to act synergistically when together: toxin A degrades the integrity of epithelial cells, allowing entry of the more potent cytotoxin B. ${ }^{1}$ The magnitude and kinetics of the host's IgG response to toxin A appears to have an important role in the clinical outcome of C. difficile infection. Individuals in whom the development of circulating antitoxin A IgG antibodies after primary infection is not prompt are likelier to experience more severe symptoms and recurrent diarrhea.

Clinical management: Diagnosis is generally based on the detection of toxin A or B in stool filtrates. Because of its quick turnaround and ease of use, a toxin-specific enzyme-linked immunosorbent assay (ELISA) is often useful. Detecting cytotoxin B in diarrheal stool filtrates by means of tissue-culture cytotoxicity assay is considered the "gold standard" for diagnosis, but results for such tests may take up to 3 days.

Treatment typically involves cessation of the offending antibiotic, initiation of oral metronidazole or vancomycin therapy, and fluid replacement. ${ }^{1}$ In severe cases the colon may perforate, necessitating colectomy. In a re- cently published series of cases from Quebec, ${ }^{2} 25.4 \%$ of patients with $C$. difficile $(68 / 298)$ who had an elevated leukocyte count or creatinine level experienced complications (megacolon, perforation, shock or colectomy); of these, $19 \%$ died within 30 days of diagnosis.

Prevention: Active and passive immunization (with intravenous immune globulin therapy) is undergoing evaluation for use in the treatment of relapsing cases of $C$. difficile. ${ }^{1}$

Preventing nosocomial transmission of $C$. difficile depends on careful attention to isolation and barrier precautions, cleaning of the physical environment all through the symptomatic period of the disease, and handwashing. ${ }^{4}$ Correct handwashing involves a 2 -minute scrub with soap to remove the surface layer of skin oil (which holds spores), followed by hand-drying with a disposable paper towel.

After a series of $C$. difficileassociated deaths in Quebec, the provincial government responded by introducing more intensive surveillance, and the Public Health Agency of Canada (see www.phac-aspc.gc.ca/c-difficile) initiated a 6-month surveillance study in teaching hospitals across the country.

\section{Erica Weir Ken Flegel CMAF}

\section{References}

1. Giannasca P, Warny M. Active and passive immunization against Clostridium difficile diarrhea and colitis. Vaccine 2004;22:848-56.

2. Pepin J, Valiquette L, Alary M, Villemure O, Pelletier A, Forget K, et al Clostridium difficile-associated diarrhea in a region of Quebec from 1991 to 2003: a changing pattern of disease severity. CMA7 2004;171(5):466-72.

3. Eggertson L, Sibbald B. Hospitals battling outbreaks of $C$. difficile. CMA7 2004;171(1):19-21.

4. Poutanen S, Simor A. Clostridium difficile-associated diarrhea in adults [review]. CMA7 2004;171(1):51-8. 